\title{
Development of Safe and Effective Botanical Dietary Supplements
}

\author{
Richard B. van Breemen* \\ UIC/NIH Center for Botanical Dietary Supplements Research \\ Department of Medicinal Chemistry and Pharmacognosy \\ University of Illinois College of Pharmacy \\ 833 S. Wood Street, Chicago IL 60612
}




\section{Abstract}

Regulated differently than drugs or foods, the market for botanical dietary supplements continues to grow worldwide. The recently implemented US FDA regulation that all botanical dietary supplements must be produced using Good Manufacturing Practice is an important step toward enhancing the safety of these products, but additional safeguards could be implemented, and unlike drugs, there are currently no efficacy requirements. To ensure a safe and effective product, botanical dietary supplements should be developed in a manner analogous to pharmaceuticals that involves identification of mechanisms of action and active constituents, chemical standardization based on the active compounds, biological standardization based on pharmacological activity, preclinical evaluation of toxicity and potential for drug-botanical interactions, metabolism of active compounds, and finally, clinical studies of safety and efficacy. Completing these steps will enable the translation of botanicals from the field to safe human use as dietary supplements. 


\section{Introduction}

In developing countries, botanical dietary supplements and traditional medicines are often the primary sources of health care for disease prevention and treatment. ${ }^{1,2}$ In the United States where $20 \%$ of adults report using botanical dietary supplements ${ }^{3}$ and to a smaller extent in Europe, these products are used primarily for health maintenance. In 2010, the worldwide market for botanical dietary supplements was reported to be $\$ 33$ Billion. ${ }^{4}$ Since enactment of the United States Dietary Supplement and Health Education Act of 1994, which exempted dietary supplements from regulation as drugs or foods, the use of these products has grown steadily in the United States, ${ }^{5}$ reaching over $\$ 6$ Billion USD in $2013 .^{6}$

Although worldwide use of botanical dietary supplements increased steadily during the last two decades, regulation varies considerably ${ }^{7}$ but in most markets requires at least botanical authentication and quality control. In the United States, botanical dietary supplements do not require proof of efficacy and do not require premarketing approval by the US Food and Drug Administration (FDA), unless drug-like efficacy is claimed. Furthermore, the safety of botanical dietary supplements remains the responsibility of the manufacturer, and safety assurance is limited to post-marketing surveillance for adverse effects. In Europe, botanical dietary supplements are regulated either as drugs or as food supplements. If therapeutic claims are made, then the European Union requires evidence of safety and efficacy for botanical dietary supplements, unless they are mixtures of botanicals with a long history of human use, in which case they are termed, "traditional herbal medicinal products," and are subject only to safety and quality requirements as in the United States. ${ }^{8}$ However, when botanical 
dietary supplements are marketed for health maintenance or promotion, then the EU regulates them as food supplements, and evidence of efficacy must be provided if health claims are made. ${ }^{9}$

In response to concerns regarding botanical integrity and quality assurance ${ }^{10}$ the US FDA recently instituted the requirement that botanical dietary supplements under its jurisdiction be prepared using good manufacturing practice (GMP). ${ }^{11}$ These guidelines complement the advertising and labeling regulations required by the US Federal Trade Commission $^{12}$ and are similar to those in effect in the EU. Enforcement of these regulations is helping to ensure that consumers are able to purchase accurately labeled botanical dietary supplements that are not contaminated with heavy metals, pesticides, herbicides, or microbes. However, these regulations do not require testing of botanical dietary supplements for potential adverse interactions with prescription medicines nor do they require evidence of efficacy.

Consumers of botanical dietary supplements expect a consistent and safe product, and current labeling guidelines and GMP requirements in major markets are helping to achieve these objectives. However, safety issues such as possible drugbotanical interactions remain unaddressed for most botanicals, and few rigorously designed clinical trials have shown efficacy. Since being established in 1999, the UIC Botanical Center for Dietary Supplements Research has promoted a set of best practices for the reproducible production and evaluation of the safety and efficacy of botanical dietary supplements (Figure 1). In this perspective, an updated version of these best practices is described that may be followed step-wise to ensure, first of all, that research on botanical dietary supplements is scientifically sound and reproducible, 
and secondly, that a botanical dietary supplement can be produced that has defined safety and efficacy.

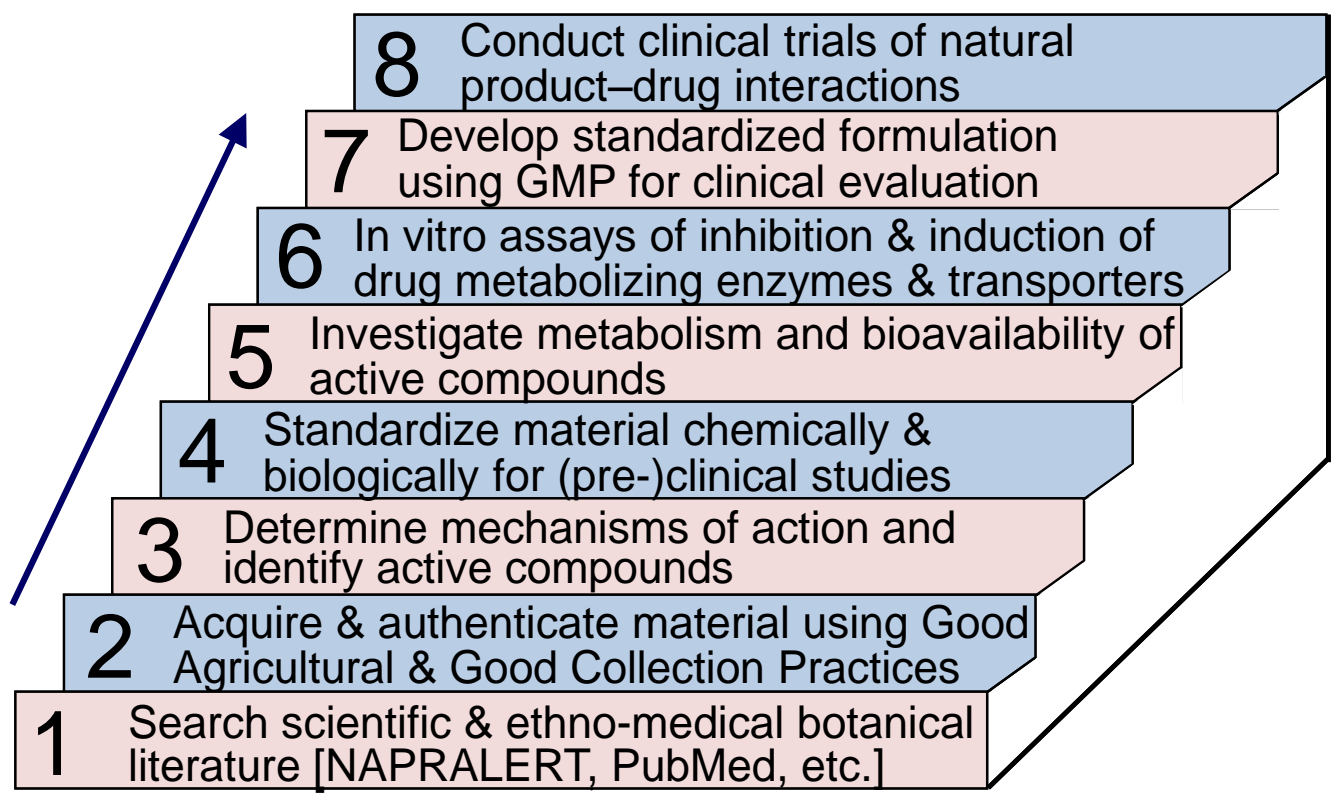

Figure 1. Steps for the development, evaluation and production of safe, reproducible and effective botanical dietary supplements.

Step 1. Critically evaluate the scientific and ethno-medical literature related to the botanicals or natural products to be studied.

The scientific and ethnobotanical literature such as PubMed, NAPRALERT, etc., should be searched to determine the history of human use of a particular botanical and what is known about its safety, efficacy and active constituents (Figure 1; Step 1). The specific parts of the plants that have a history of human use should be ascertained, as human experience might indicate better efficacy and/or lower toxicity for certain parts such as fruits, roots or leaves. For example, soybeans (Glycine max) are used instead of roots, stems or leaves in soy-based dietary supplements as well as in foods, and roots of licorice species such as Glycyrrhiza glabra are used instead of the aerial 
portions of the plant. Another example is the tomato (Solanum lycopersicum L.) from which the ripe fruit is used to prepare lycopene-rich dietary supplements, but the leaves or even the unripe fruits contain toxic alkaloids such as dehydrotomatine and $\alpha$ tomatine. $^{13}$

Step 2. Acquire and authenticate natural product material using Good Agricultural and Good Collection Practices.

Good collection practice for wild crafted botanicals will ensure sustainability, and good agricultural practice for cultivated botanicals will reduce the risks of contamination by pesticides, heavy metals, infectious agents, etc. As part of these practices, all plants used for the production of dietary supplements should be botanically authenticated to avoid misidentification. The scientific and clinical literature concerning botanical dietary supplements, especially clinical case reports, is sometimes missing the sources of the materials under study and often lacks evidence of species authentication. Without such information, these studies cannot be reproduced and validated. This step follows both the NIH National Center for Complementary and Integrative Health guidelines for assuring a safe, authenticated botanical as prescribed in the "NCCIH Policy: Natural Product Integrity," ${ }^{14}$ the World Health Organization's guidelines for assessing quality of herbals, ${ }^{15}$ and the US FDA requirement that all botanical dietary supplements used by consumers must be manufactured using GMP (Figure 1, Step 6;) which includes botanical authentication.

Using microscopic, macroscopic and/or neuroleptic methods, a botanist should determine the genus and species of raw plant materials, and comparison with voucher specimens is highly recommended. Such examination will ensure that the appropriate 
species and part of the plant has been obtained. Suppliers of botanical materials sometimes inadvertently ship the wrong part of the plant or misidentify the species being provided. Other identification approaches may be used such as DNA bar coding and chemical fingerprinting. DNA analysis using RAPD (randomly amplified polymorphic DNA), RFLP, ARMS, CAPS, AFLP, DAF, ISSR, SSR, sequencing, hybridization and microarrays can be helpful, especially when the raw botanicals have been chopped, blended or powdered. ${ }^{16,17}$ Chemical analyses using techniques such as GC-MS, ${ }^{18}$ high performance thin layer chromatography, ${ }^{19} \mathrm{NMR},{ }^{20}$ immunoassay, ${ }^{21}$ MALDI MS, ${ }^{22}$ UHPLC$\mathrm{UV}^{23}$ and HPLC-MS ${ }^{24,25}$ provide independent botanical "fingerprinting" through characterization of plant secondary metabolites. Comparison of this chemical profile with reference standards may be used for quality assurance and botanical identification. When DNA has been removed through extraction, enzymatic or chemical hydrolysis, or if degradation has occurred during processing such as sterilization, chemical fingerprinting alone can still be used for botanical identification and authentication. ${ }^{26}$ An example of chemical fingerprinting and authentication of two licorice species using UHPLC-MS/MS is shown in Figure 2.

Misidentification of the botanical species not only compromises subsequent scientific investigation, but it can have tragic results, as was the case of a botanical dietary supplement preparation sold for weight loss in Belgium in 1991. In that case, Stephania tetranda was accidentally replaced by Aristolochia fanchi apparently due to similarities in the Chinese common names, ${ }^{27}$ and $>100$ young women developed nephropathy and some suffered renal and urinary tract cancers. ${ }^{28}$ Aristolochic acid in A. fanchi can cause nephropathy at daily exposures of only a few $\mu \mathrm{g} / \mathrm{kg} .{ }^{29}$ In another example, two women 
suffered atrioventricular block after ingesting botanical dietary supplements of the same brand name and lot number. Immunoassay of serum samples detected digitalis, and a botanical dietary supplement used by both subjects containing 14 herbal ingredients tested positive for cardiac glycosides. Subsequent testing of the ingredients used to prepare the supplement using LC-MS determined that the botanical constituent labeled as "plantain" was actually Digitalis lanata based on the identification the cardiac glycosides lanatoside $A$ and lanatoside $C{ }^{30}$

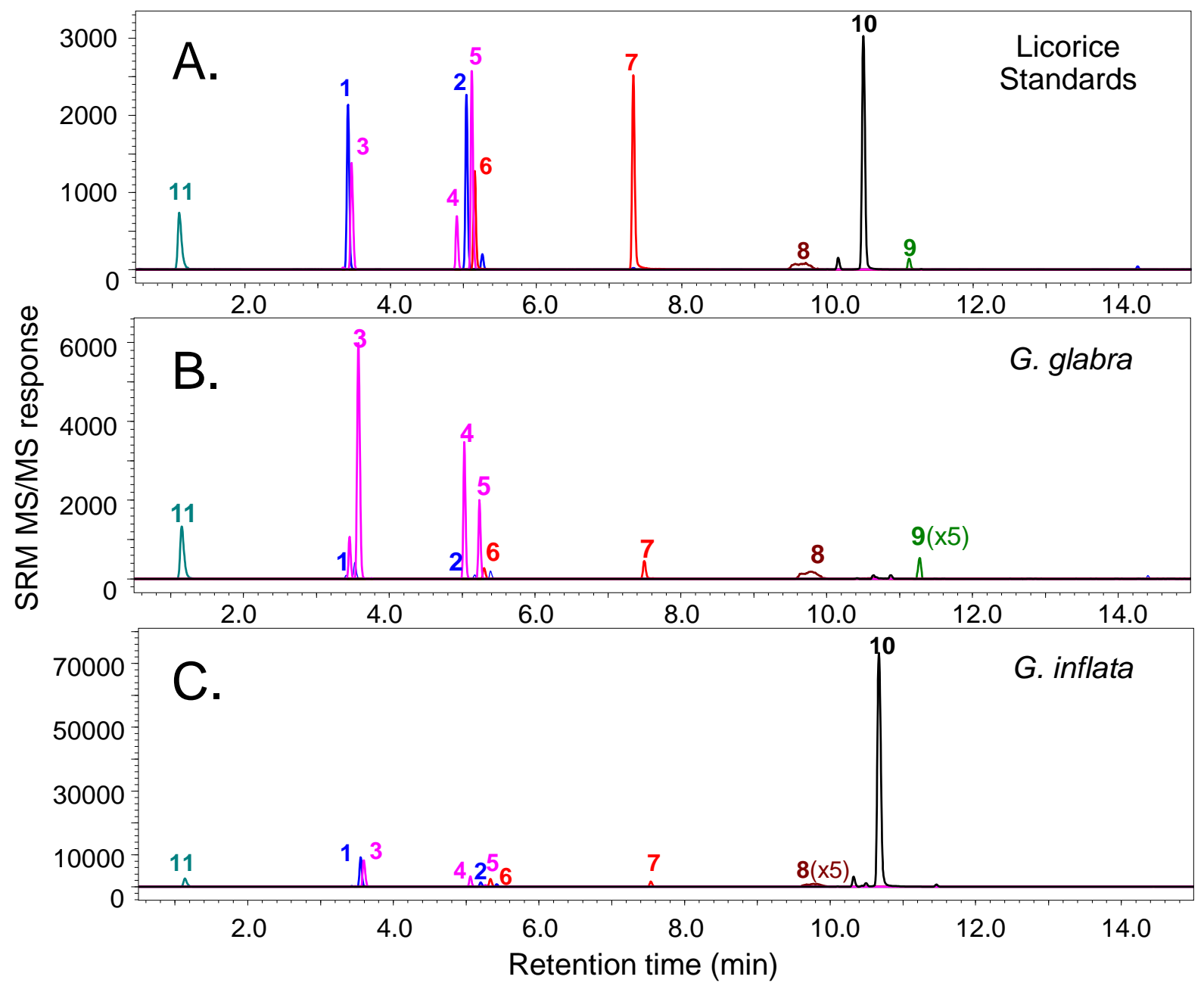

Figure 2. UHPLC-MS/MS chemical characterization of two licorice species. By comparison of the UHPLC-MS/MS profiles of A) a mixture of 13 standards representing 
characteristic licorice secondary metabolites with extracts of two licorice species, the botanical species were distinguished and uniquely identified as B) Glycyrrhiza glabra; and C) G. inflata. Whereas all of the detected compounds indicate the genus as Glycyrrhiza, glabridin (9) and licochalcone A (12) distinguish the species and G. glabra and G. inflata, respectively. Key: 1. Liquiritin; 2. isoliquiritin; 3. liquiritin apioside; 4. isoliquiritin apioside; 5. licuraside; 6. liquiritigenin; 7. isoliquiritigenin; 8. glycyrrhizin; 9. glabridin; 10. licochalcone A; 11. 2-(4-hydroxybenzyl)malonic acid.

Among the requirements of EU and United States regulators, and others, is botanical authenticity. However, the producers of botanical dietary supplements have considerable flexibility regarding how to characterize and identify the botanical species used in their products. Nevertheless, lack of evidence of botanical authenticity is one of the most common violations cited during regulatory inspections. ${ }^{31}$

Assuming that all processed botanicals in finished dietary supplements contain intact botanical DNA, the Attorney General of the State of New York in February 2015 ordered four large distributors of botanical dietary supplements ${ }^{32}$ and then several manufacturers of these products ${ }^{33}$ to stop selling several saw palmetto, St. John's wort, garlic, ginseng, and Echinacea products after DNA bar code testing failed to indicate the expected botanical species. One of the limitations of the testing carried out in this case is that processed botanicals such as those prepared by using solvent extraction, pasteurization or even hydrolysis might not contain intact DNA or even large fragments of DNA. To put this in perspective, DNA bar coding was used to test soy sauce for evidence of genetically modified soybeans, ${ }^{34}$ but no soybean DNA of any kind could be detected. There are testing approaches available that complement DNA bar coding 
such as chemical fingerprinting (Figure 2) that may be used to establish botanical authenticity of even processed botanical dietary supplements or foods.

Step 3. Determine mechanisms of action, and identify active compounds.

Appropriate bioassays should be utilized to determine mechanisms of action and to identify active chemical constituents. The bioassays should include evaluation of possible synergy between botanical constituents as well as the determination of potential toxic effects and any toxic botanical constituents. Antagonism as well as synergy of pharmacological targets for active compounds should be evaluated for the expected targets as well as for selected receptors/targets that might be responsible for side effects. For example, emerging transcriptomics, metabolomics and proteomics assays should eventually be useful in identifying unanticipated effects and targets of active natural products contained in botanical dietary supplements.

Identification of active compounds is necessary prior to the chemical standardization of a complex natural product mixture, and mechanisms of action should be determined for biological standardization (Step 4). Bioassay-guided fractionation ${ }^{35}$ or higher-throughput types of assays such as pulsed ultrafiltration LC-MS (PUF-MS) ${ }^{36}$ or magnetic bead affinity mass spectrometry-based screening ${ }^{37}$ may be used to identify the active compounds that function by a specific mechanism of action within natural product mixtures. The most popular approach to the identification of active natural products is bioassay-guided fractionation (Figure 3). During this process, natural product extracts are screened using a variety of bioassays, and if an extract produces a positive response in a particular assay, then the extract is fractionated using chromatography, and 
each fraction is tested using the same assay for activity. The active fraction is fractionated again, and the process is repeated until a single compound is isolated for spectroscopic characterization and identification.

As higher-throughput alternatives to bioassay-guided fractionation, mass spectrometry-based screening assays have been developed (Figure 3) such as PUF-MS ${ }^{36}$ and magnetic bead affinity screening mass spectrometry ${ }^{37}$ (Figure 4). MS-based screening eliminates the laborious process of bioassay-guided fractionation by using an affinity extraction with immediate characterization of the active compounds within a complex botanical extract. High resolution accurate mass measurements provide elemental compositions of ligands to receptors or enzymes, and product ion tandem mass spectra provide structural information. Because PUF-MS and magnetic bead affinity MS screening involve HPLC or UHPLC separation, the chromatographic retention times of the active species are known and may be used to guide the their isolation for additional structural determination such as NMR. As an example, the process of magnetic bead MS-based screening is summarized in Figure 4. 


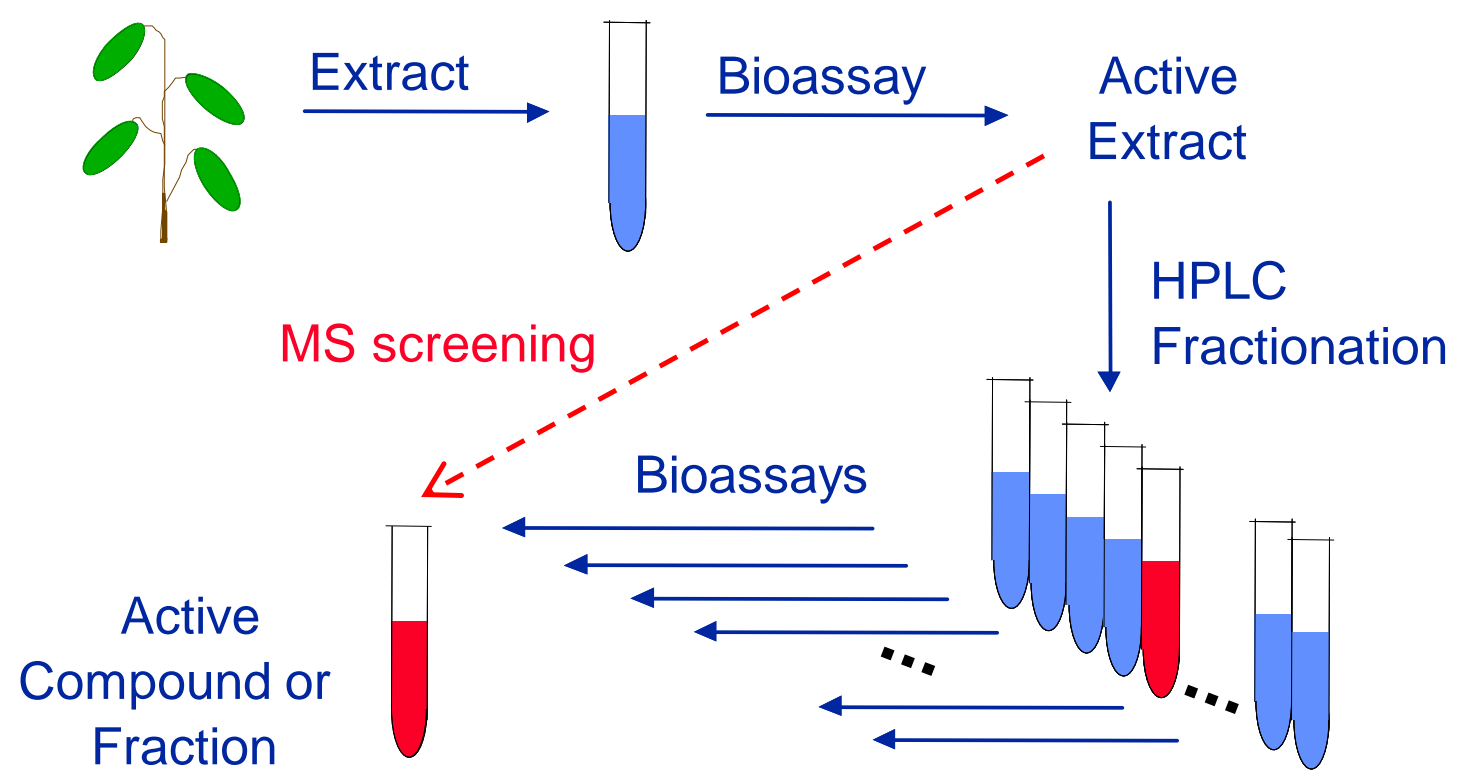

Figure 3. To identify active compounds in complex mixtures of natural products, the reiterative process of bioassay-guided fractionation is typically used. Alternatively, mass spectrometry-guided approaches such as PUF-MS or magnetic bead MS screening may be used to expedite this process. 
A. Experiment with immobilized receptor $(\mathrm{R})$

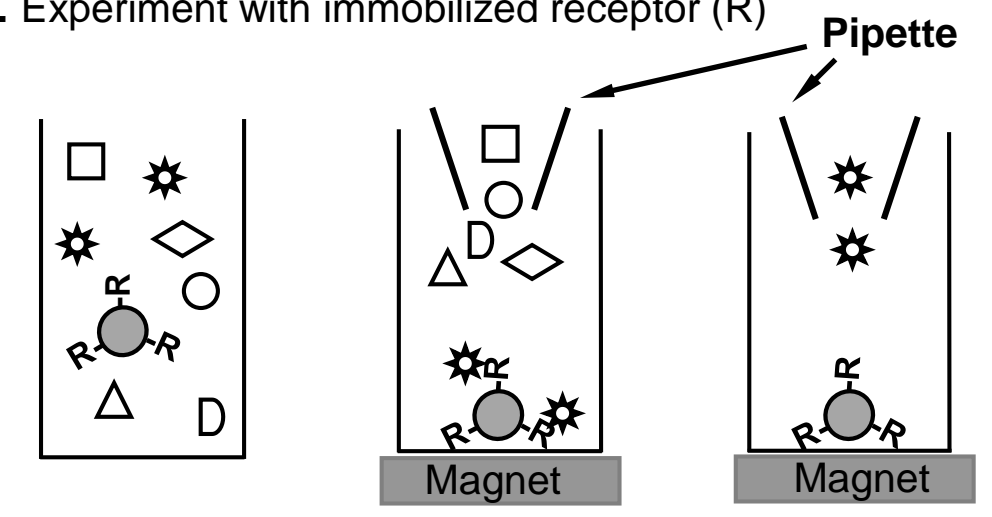

Incubation
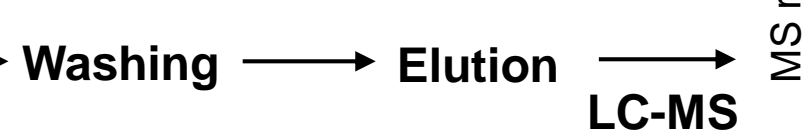

B. Control without receptor
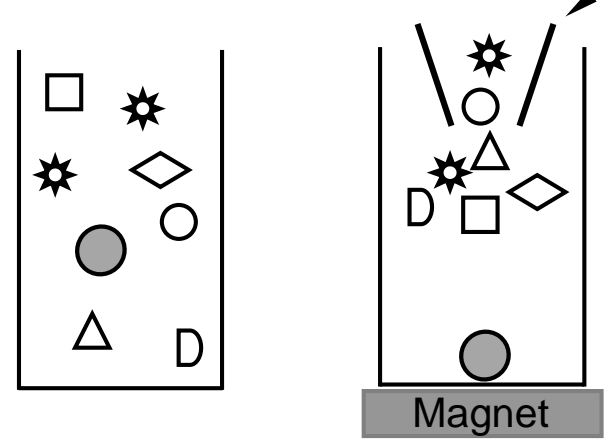

Pipette

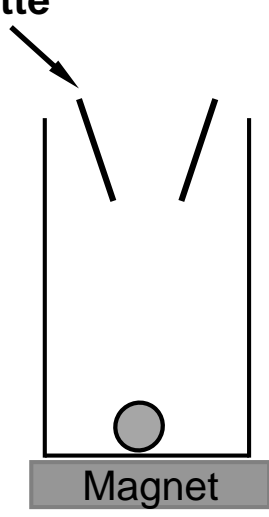

Control

Retention time

Figure 4. Magnetic bead LC-MS screening for the identification of ligands to a receptor (R). Magnetic beads containing A) immobilized receptor; or B) no receptor (control) are incubated with a botanical extract. Application of a magnetic field to the particles facilitates the rapid separation of unbound compounds in the extract from the ligands bound to the immobilized receptor. Finally, the ligands are released from the receptor using organic solvent and characterized using LC-MS. 
Step 4. Chemical and biological standardization.

To ensure a reproducible product for clinical trials as well as for consumers, botanical dietary supplements should be standardized chemically based on active compounds and standardized biologically through testing using the appropriate bioassays. ${ }^{38}$ If the active constituents are as yet unknown, then marker compounds that are representative of the botanical species in the supplement may be used as surrogates during chemical standardization. Chemical standardization usually utilizes chromatography, such as HPLC-UV, HPLC-evaporative light scattering detection, or (U)HPLC-MS/MS to measure levels of active compounds and any marker compounds that might be helpful for the preparation of a reproducible product.

To complement chemical standardization, biological standardization using specific in vitro and in vivo bioassays ensure that the dietary supplement will have reproducible pharmacological and physiological activities. Biological standardization may involve in vitro testing such as enzyme assays, receptor binding assays, cell-based gene expression assays, or in vivo assays such as the use of laboratory animal models. Together, these chemical and biological standardization assays help ensure the reproducibility of the dietary supplements by other laboratories for research purposes as well as enabling the production of reproducible products for consumers.

As an example, Krause, et al. ${ }^{39}$ reported a model approach for chemical and biological standardization of a hop (Humulus lupulus L) dietary supplement under investigation as an estrogenic alternative to conventional hormone therapy for menopausal women. In this case, the prenylated phenols xanthohumol, isoxanthohumol, 6-prenylnaringenin, and 8-prenylnaringenin were identified as active 
constituents and then used for chemical standardization using LC-MS/MS (Figure 5), while cell-based bioassays of chemoprevention and estrogenicity were used for biological standardization.

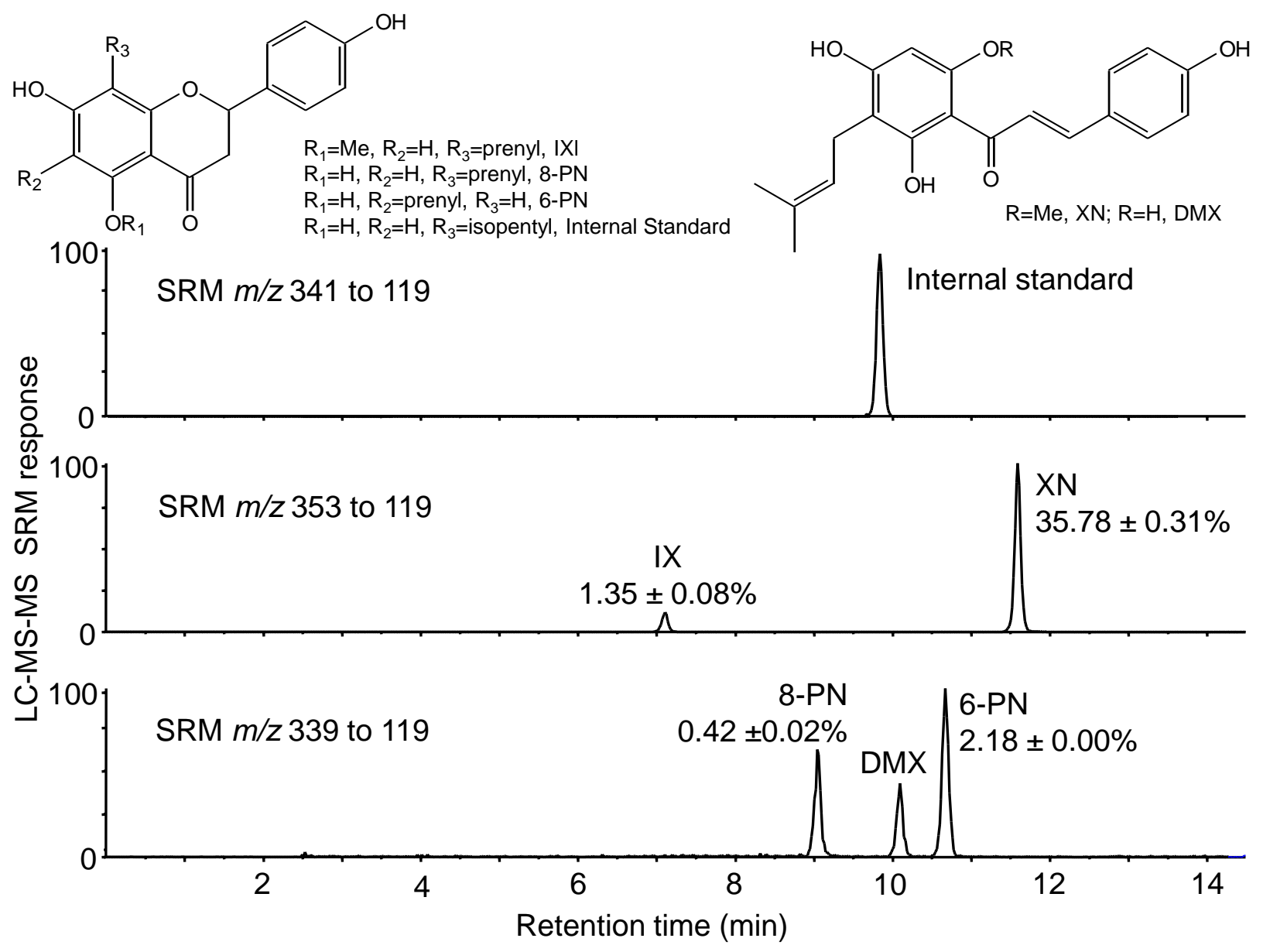

Figure 5. LC-MS/MS (reversed phase HPLC interfaced with electrospray and tandem mass spectrometry with selected reaction monitoring, SRM) measurement of prenylated phenols during the chemical standardization of a hop dietary supplement. Based on an external standard curve with normalization to an internal standard (8isopentylnaringenin), levels of isoxanthohumol (IX), 8-prenylnaringenin (8-PN), 6prenylnaringenin (6-PN), and xanthohumol (XN) were determined. (From reference 39 with permission). 
As another example, Piersen et al. ${ }^{40}$ standardized an extract of the aerial parts of red clover (Trifolium pratense L.) chemically to estrogenic and proestrogenic isoflavones consisting of deconjugated daidzein, genistein, formononetin, and biochanin A. Biological standardization was carried out based on estrogenic activity using cellfree estrogen receptor- $\alpha$ and estrogen receptor- $\beta$ assays and in Ishikawa and S30 cellbased assays as well as in vivo assays using an ovariectomized rat model. The standardized extract was then used in Phase $\mathrm{I}^{40}$ and Phase $\mathrm{II}^{41}$ clinical trials to evaluate the safety and potential efficacy of red clover in the prevention of symptoms such as hot flashes in menopausal women.

The US Pharmacopeial Convention (USP) has, since its inception in 1820, provided guidance on standardization of botanical dietary supplements. ${ }^{42}$ USP monographs on many botanicals are available that include procedures for standardization. USP Dietary Supplement Reference Standards are available to facilitate standardization as well as botanical authentication. The AOAC International also provides guidance on botanical identification and chemical standardization of botanical dietary supplements. ${ }^{43}$ Official AOAC International methods for botanical standardization are published in the Journal of the AOAC International, and analytical methods for the authentication and standardization of botanical dietary supplements appear in a variety of other analytical and natural products journals on a regular basis. As new active compounds are identified in botanical dietary supplements, they should be included in updated chemical standardization methods. As with assays for chemical standardization, the development of new or improved bioassays for biological standardization will continue to be an on-going process. 
Step 5. Absorption, metabolism and bioavailability of active compounds.

Active compounds and other significant natural products in a dietary supplement should be investigated for absorption and metabolism. Bioavailability, which includes contributions from absorption, intestinal metabolism and hepatic first pass metabolism, is an important but often overlooked determinant of efficacy of botanical dietary supplements. Only those compounds that cross the intestinal epithelium are likely to produce systemic effects, and lack of absorption might explain why many clinical trials of botanical dietary supplements as well as isolated natural products have shown no pharmacological effects in spite of in vitro studies suggesting otherwise.

For example, in vitro assays have suggested hepatoprotective and antioxidant activity for flavolignans such as silybins A and B in milk thistle (Silybum marianum) dietary supplements. However, Phase I clinical trials of milk thistle have shown that the bioavailability of each of these compounds is $<0.5 \%{ }^{44}$ and that the half-life is short $(<2$ hours) due to rapid phase II conjugation. ${ }^{45}$ These values suggest that dietary supplements containing milk thistle should have weak and short-acting benefits. In contrast, hop dietary supplements containing prenylated phenols like xanthohumol (a chemoprevention agent) and 8-prenylnaringenin (a botanical estrogen) have half-lives of $\sim 20$ hours indicating the possibility of extended activity before excretion as phase II conjugates. ${ }^{46,47}$

The poor bioavailabilities of milk thistle flavolignans resulting from poor absorption and rapid phase II conjugation could have been predicted prior to clinical studies using in vitro assays such as the Caco-2 cell monolayer model of intestinal permeability and transport or in vivo animal models. For example, the Caco-2 model was used to study the hop prenylated phenols and correctly predicted rapid absorption as well as phase II 
conjugation. ${ }^{48}$ The Caco-2 cell monolayer model of intestinal permeability and transport is a standard approach to predict intestinal absorption of drugs and drug candidates that shows good correlation with human drug absorption..$^{49,50}$

Not only useful for testing drugs and isolated natural products, the Caco-2 cell model may be used in combination with LC-MS for the simultaneous measurement of intestinal permeabilities of multiple natural products in complex extracts. For example, Caco-2 permeability studies of an extract of black cohosh (Actea racemosa) predicted that the characteristic triterpene glycosides would be absorbed slowly whereas the caffeic acid derivatives should have minimal absorption. Subsequent Phase I and Phase II clinical studies confirmed the moderate to low bioavailability of triterpene glycosides from black cohosh such as 23-epi-26-deoxyactein ${ }^{51}$ while finding no oral bioavailability of the caffeic acids. ${ }^{52}$ Metabolism of natural products, especially phase II conjugation reactions such as sulfation and glucuronidation that often occur in the intestine during absorption, can also be investigated using Caco-2 cell monolayers. For example, the stilbene resveratrol, which occurs in grapes, peanuts, cranberries, blueberries, and bilberries, ${ }^{53}$ is metabolized primarily to phase II sulfate and glucuronic acid conjugates, and this process begins in the intestine as indicated by studies with Caco-2 cells (Figure 6). ${ }^{54}$ 


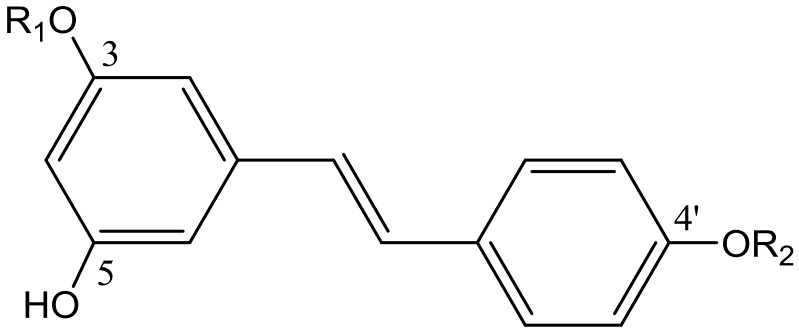

trans-resveratrol: $\mathrm{R}_{1}=\mathrm{R}_{2}=\mathrm{H}$

trans-resveratrol-3-O-glucuronide: $\mathrm{R}_{1}=$ glucuronic acid, $\mathrm{R}_{2}=\mathrm{H}$ Caco-2 cells, hepatocytes

trans-resveratrol-4'-O-glucuronide: $\mathrm{R}_{1}=\mathrm{H}, \mathrm{R}_{2}=$ glucuronic acid hepatocytes

trans-resveratrol-3-sulfate: $\mathrm{R}_{1}=$ sulfate, $\mathrm{R}_{2}=\mathrm{H}$

Caco- 2 cells

trans-resveratrol-4'-sulfate: $\mathrm{R}_{1}=\mathrm{H}, \mathrm{R}_{2}=$ sulfate

none observed

Figure 6. Resveratrol phase II metabolism by human Caco-2 cells ${ }^{54}$ or human hepatocytes. ${ }^{55}$

Metabolism of natural products usually results in the formation of polar metabolites that are pharmacologically less active and can be more rapidly excreted into bile or urine. Less frequently, metabolism can produce compounds that are more active than their precursors. As with preclinical studies of drug metabolism, human and rat liver microsomes and human hepatocytes are ideal for the investigation of phase I and phase II hepatic metabolism of natural products from dietary supplements. In vivo animal studies may be used to test these in vitro predictions prior to clinical studies. Due to sensitivity, selectivity and speed, LC-MS/MS and UHPLC-MS/MS have become central to all aspects of preclinical and clinical studies of drug metabolism. This is also the case for metabolism of natural products in botanical dietary supplements. As an example, the phase I and phase II metabolites of the natural product and chemoprevention agent resveratrol were determined using human liver microsomes and human hepatocytes using LC-MS/MS (Figure 6). ${ }^{55}$ Although no phase I metabolites were detected, phase II glucuronic acid conjugates 
were formed using hepatocytes, which complemented the sulfate conjugates formed using the intestinal Caco-2 cells. ${ }^{54}$ Resveratrol glucuronides and sulfates have subsequently been identified in human serum and urine, indicating absorption after oral administration followed by rapid phase II conjugation and elimination. ${ }^{56}$

Identifying the enzymes responsible for metabolic transformation of natural products contained in botanical dietary supplements is important, as they might be inhibited or induced through this interaction (see enzyme inhibition and induction, Step 6). Consequently, the metabolic transformation, serum levels and bioavailability of some therapeutic agents might become altered. Recombinant enzymes are a useful tool for determining enzymes that are involved in specific metabolic transformations. For example, recombinant human cytochromes $\mathrm{P} 450$ were used to identify the enzymes responsible for the formation of the major phase I metabolites of the licorice compound isoliquiritigenin, ${ }^{57}$ and recombinant human UDP-glucuronyltransferases were used to identify the enzymes catalyzing formation of three phase II glucuronides of this natural chemoprevention agent. ${ }^{58,59}$ Alternatively, human liver microsomes may be used with monoclonal antibody inhibitors of cytochrome P450 phase I enzymes to identify those that form phase I metabolites of natural products. Originally developed by Harry Gelboin at the National Institutes of Health, ${ }^{60}$ these monoclonal antibodies are now available from commercial sources. As an example, the monoclonal antibody inhibitor approach was used to identify cytochrome P450 enzymes involved in the metabolism of the hop prenylated flavonoids isoxanthohumol and 8-prenylnaringenin. ${ }^{61}$

Prior to absorption of orally administered natural products contained in botanical dietary supplements, gastrointestinal tract microbiota can metabolize them. These microbial 
metabolites might be identical or different from those formed by human enzymes. Furthermore, these metabolites can be more active or less pharmacologically active than their precursors. Using hops as an example, the weakly estrogenic prenylated phenol IX (Figure 5) can be O-demethylated by intestinal microbiota to form the potent estrogen 8PN. ${ }^{62}$ This metabolic conversion by intestinal microbiota, observed in only one-third of tested individuals, ${ }^{62}$ is similar to that catalyzed in the liver by human CYP1A2. ${ }^{61}$ In the case of soy isoflavones, weakly estrogenic daidzein can be metabolized to the more potent estrogen equol by intestinal microbiota in approximately one-third of individual consuming a Western diet and in two-thirds of people eating an Asian diet. ${ }^{63}$ In contrast to the intestinal microbiome, human enzymes do not convert daidzein to equol.

The composition of the intestinal microbiome is not static and can be altered by diet and by the consumption of probiotics. The regular consumption of botanical dietary supplements can also alter the composition of intestinal microbiota. For example, supplementation with Echinacea purpurea was found to increase total aerobic but not anaerobic bacteria in the human gastrointestinal tract. ${ }^{64}$ The role of intestinal microbiota in the metabolism of natural products contained in botanical dietary supplements is a relatively new area of investigation, but important contributions have already been documented that indicate potential for large inter-individual variations.

Reactive metabolites can covalently modify DNA and proteins and are a potential cause of toxicity, especially hepatotoxicity. To overcome the problem that electrophilic metabolites are short-lived and cannot usually be isolated for spectroscopic characterization, reactive drug metabolites can be generated in vitro using microsomal cytochrome P450 enzymes and the cofactor NADPH, trapped immediately as conjugates 
with the biological nucleophile glutathione or $\mathrm{N}$-acetylcysteine, and then detected and characterized using LC-MS/MS. ${ }^{65}$ This approach has been developed into a screening assay suitable for extracts of botanical dietary supplements ${ }^{66}$ and has been applied to a variety of botanical dietary supplements including sassafras, ${ }^{67}$ kava (Piper methysticum Forst.), ${ }^{68}$ and black cohosh (Actea racemosa) ${ }^{52}$ For example, glabridin (a natural product constituent of licorice, Glycyrrhiza glabra) can be oxidized by CYP3A4 to form an electrophilic quinone methide and trapped as isomeric glutathione conjugates (Figure 7) ${ }^{69}$
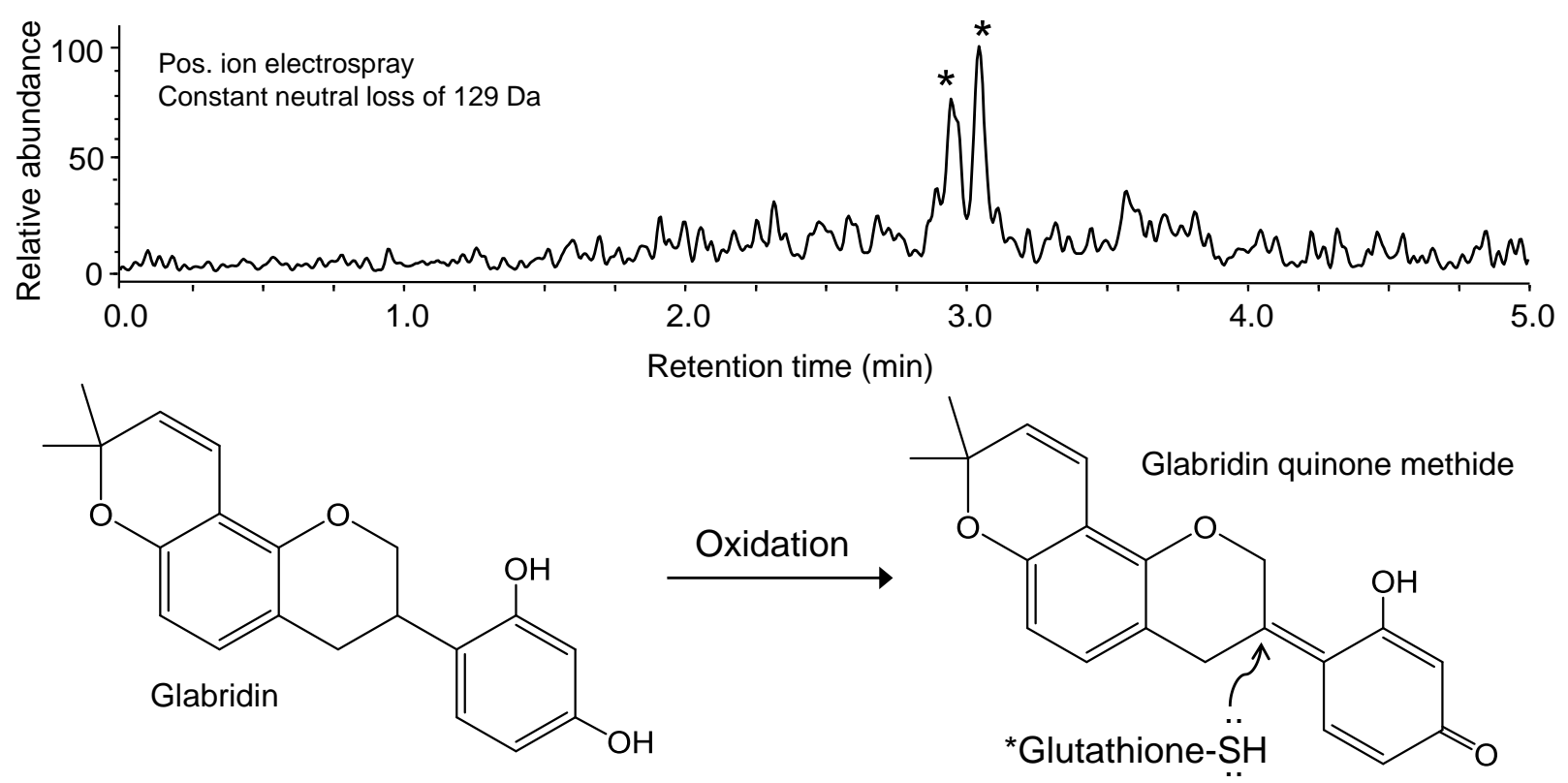

Figure 7. UHPLC-MS/MS detection of glutathione conjugates of oxidized glabridin from licorice (G. glabra) formed during incubation with human liver microsomes, NADPH and glutathione. Two glutathione conjugates $\left({ }^{*}\right)$ were formed by nucleophilic addition of glutathione from above or below the plane of the ring system and then detected selectively using UHPLC combined with positive ion electrospray tandem mass spectrometry with constant neutral loss scanning for the characteristic glutathione fragment ion of $[\mathrm{MH}-129]^{+}$. (From reference 69.) 
A significant challenge to carrying out absorption, metabolism and bioavailability studies of botanical dietary supplements is evaluating these products as complex mixtures. Although specific natural products can be isolated and then evaluated like a drug candidate, this approach misses possible interactions such as synergism between constituents. Therefore, whenever possible, investigations of the absorption, metabolism and bioavailability of compounds in botanical dietary supplements should be carried out using mixtures of constituents as they are actually used by consumers. The approaches and assays describe above such as the Caco-2 cell monolayer model of intestinal permeability and UHPLC-MS/MS assay for metabolic activation are entirely suitable for mixture analysis. In vivo metabolism studies may also utilize complex botanical products. Although most in vitro approaches to investigate enzymatic transformation such as hepatocytes and recombinant enzymes are more compatible with isolated natural products, preclinical studies of inhibition and induction of drug metabolizing enzymes may be carried out using mixtures as described in the next section.

Step 6. Preclinical assays of inhibition and induction of drug metabolizing enzymes and transporters.

Because the safe and effective uses of most therapeutic agents depend on predictable rates and routes of absorption, metabolism and excretion, consumption of botanical dietary supplements that interfere with any of these processes (drug-botanical interactions) can have harmful consequences. To determine whether natural products contained in botanical dietary supplements inhibit specific cytochromes P450, assays have been developed utilizing human hepatocytes, human liver microsomes and recombinant enzymes. This approach is similar to that recommended by the FDA for the investigation of 
cytochrome P450 enzyme inhibition by drugs, ${ }^{70}$ and includes determination of the effects of the test agent (here a botanical dietary supplement instead of a drug) on the rates of metabolism of probe substrates by CYP1A2, CYP3A4/5, CYP2B6, CYP2C8, CYP2C9, CYP2C19, and CYP2D6. Probe substrates recommended by the FDA are incubated with the appropriate enzyme(s) and their rates of metabolism are measured with and without each test agent. Examples of probe substrates for each enzyme include the following: CYP1A2 (phenacetin), CYP2B6 (buprion), CYP2C8 (amodiaquine), CYP2C9 (tolbutamide), CYP2C19 (mephenytoin), CYP2D6 (dextromethorphan), and CYP3A4 (midazolam).

When inhibition of specific cytochrome P450 enzymes by a botanical dietary supplement extract is identified, the inhibition constants can then be determined using recombinant enzymes. Additional studies using approaches such as bioassay-guided fractionation can be carried out to identify the responsible natural products within an inhibitory extract. Analogous assays using probe substrates and microsomes, recombinant enzymes or hepatocytes can be used to determine if botanical extracts inhibit phase II enzymes such as UDP-glucuronosyltransferases and sulfases.

For example, probe substrates with human liver microsomes and recombinant enzymes were used to determine that hop (Humulus lupulus) dietary supplements can inhibit the drug metabolizing enzymes CYP1A2, CYP2C8, CYP2C9, and CYP2C19. ${ }^{71}$ In another example, trans-resveratrol was found to be a weak inhibitor of CYP3A4 and CYP2C19. ${ }^{72}$ Finally, eight triterpene glycosides of black cohosh were identified as competitive CYP3A4 inhibitors with $\mathrm{IC}_{50}$ values ranging from 2.3-5.1 $\mu \mathrm{M}$, while the black cohosh alkaloids protopine and allocryptopine were identified as competitive CYP2D6 inhibitors with $\mathrm{K}_{\mathrm{i}}$ values of 78 and $122 \mathrm{nM}$, respectively. ${ }^{73}$ 
Many reports of drug-botanical interactions are based on in vitro assays alone without considering bioavailability and clinical significance. As a result, in vitro drug metabolism inhibition data sometimes correlate poorly with human clinical trial data of drugbotanical interactions. This incongruity is primarily caused by poor bioavailability of many of the natural products contained in botanical dietary supplements. Therefore, it is critically important that cell-based (Caco-2 and hepatocyte) and/or animal bioavailability studies (Step 5) be carried out to complement these enzyme assays prior to embarking on expensive clinical trials. For example, ginseng (Panax ginseng) was predicted using in vitro assays with recombinant enzymes to inhibit CYP3A4, CYP2C9, CYP2C19, CYP2D6 ${ }^{74}$ whereas clinical studies with ginseng showed no drug-botanical interactions. ${ }^{75}$ In another example, a milk thistle extract containing flavolignans was reported to inhibit CYP3A4, ${ }^{76}$ although a subsequent clinical trial of drug-botanical interactions found no such inhibition, ${ }^{77}$ probably as a result of the low bioavailability of these compounds. ${ }^{44,45}$

Induction of drug metabolizing enzymes by botanical dietary supplements has been investigated infrequently compared with enzyme inhibition but can also have significant consequences. To investigative possible induction of cytochromes P450 and phase II enzymes such as UDP-glucuronosyltransferases by drugs, the US FDA recommends using primary human hepatocytes or attachable cryopreserved hepatocyte cultures from at least 3 donors and testing for up-regulation of enzyme mRNA. ${ }^{78}$ This approach to predicting enzyme induction by drugs is also applicable to botanical dietary supplements. In the case of cytochromes P450, determination of induction of 3 major drug-metabolizing enzymes, CYP1A2, CYP2B6 and CYP3A4 are recommended. Note that CYP2C, CYP2B and the drug transporter P-gp are typically co-induced with CYP3A. With respect to induction of 
phase II enzymes and drug transporters, human hepatocytes and similar mRNA approaches may be used. ${ }^{79,80,81}$

Although the US FDA currently recommends mRNA measurements of enzyme expression, enzyme functional assays may be used instead to determine induction of drug metabolizing enzymes. Because mRNA might be induced while at the same time the corresponding enzymes might have limited functionality, both mRNA expression assays as well as functional enzyme assays should be carried out. Among possible causes of nonfunctional enzymes in these systems is mechanism-based irreversible inhibition by natural products, which would not be evident if mRNA alone is measured. As an example of a well-studied drug-botanical interaction, dietary supplements containing St. John's wort (Hypericum perforatum) have been shown in multiple pre-clinical studies, clinical case reports and clinical studies to induce CYP3A4 and cause drugs that are CYP3A4 substrates to be metabolized faster than normal. ${ }^{82,83}$

In addition to inhibition of drug metabolizing enzymes by botanical dietary supplements, there is also the potential for inhibition or induction of drug transporters. To determine if isolated natural products or extracts of botanical dietary supplements induce or inhibit intestinal transporters (P-gp, BCRP, OATP1B1, OAT1/OAT3, OCT2, etc.), the Caco2 cell monolayer system may be used. $^{70}$ As with hepatocyte studies, mRNA and/or functional assays may be used to determine if transporters are up-regulated, downregulated or inhibited. Emerging approaches using HepaRG cells or transfected cell lines should also be considered as these technologies develop.

To complement these studies on the effects of botanical dietary supplements on drug metabolism and transport, the extent to which botanical natural products compete with 
drugs bound to serum proteins should be investigated. The displacement of drugs from serum proteins by tightly binding natural products can transiently increase the serum concentrations of therapeutic agents causing toxicity as well as increasing their rates of clearance. For this reason, botanical compounds which are found to be absorbed should also be tested for serum protein binding.Natural products contained within botanical dietary supplements that are determined to cause drug interactions should be identified and measured as part of the standardization process. Potential drug-botanical interactions could then be predicted and controlled through prudent use of the supplement. Alternatively, the problematic natural products could be removed (or at least minimized) from the botanical dietary supplement through processing (like decaffeination of coffee) or by substitution of cultivars and varieties of the botanical species that produce little of none of the interacting compounds.

Step 7. GMP preparation of standardized formulation.

After standardization as described in Step 4, the production of botanical dietary supplements using GMP is an essential step in ensuring the safety and efficacy of these products. GMP preparation enhances the safety of consumers and human subjects in clinical trials by preventing contamination of the capsules/tablets by pharmaceutical compounds, microbes, pesticides, herbicides, heavy metals, and other foreign matter. To ensure the reproducibility of in vivo research using botanical dietary supplements, GMP should also be used for the preparation of dosage forms intended for use in preclinical animal studies as well as for clinical studies. Reproducibility of in vivo studies has been a major issue with early research in this field and can be enhanced by using GMP protocols such as authenticating the botanicals used in the formulation, by 
verifying that the capsules/tablets contain uniform dosages, by requiring uniform dissolution rates, and by ensuring that the material remains stable until and during use.

Analyses of botanical dietary supplements for heavy metals, pesticides, herbicides, and microbial contamination are routine and can be carried out by contract laboratories or by appropriately equipped analytical and microbiology laboratories. These approaches have been reviewed previously. ${ }^{10}$ Briefly, metal analysis is typically carried out using inductively coupled plasma mass spectrometry or atomic absorption spectroscopy. Quantitative analyses of pesticide and herbicide residues are usually based on gas chromatography with either flame ionization detection, electron capture detection, or mass spectrometric detection. Microbial content can be measured using established tests for food products, and mycotoxin content (toxic fungal secondary metabolites) can be measured using LC-MS/MS. ${ }^{84}$

With final implementation of GMP requirements for botanical dietary supplements by the US FDA in $2010,{ }^{11}$ Step 7 has become standard in this industry. To minimize the financial burden to small companies, GMP requirements were implemented in a staggered manner over a 3-year period beginning with large corporations and eventually encompassing small companies. ${ }^{85}$ Enforcement of GMP requirements has been active, and reports of FDA warning letters are published on-line. ${ }^{31}$

\section{Step 8. Clinical investigations}

Although studies using in vitro and in vivo models as described above are necessary, the safety and efficacy of botanical dietary supplements must ultimately be determined in humans. As with drug trials, clinical trials of botanical dietary supplements may be carried out in a series of escalating phases, each of which involves larger 
populations of human subjects. Phase I clinical studies are short-term and involve small groups of subjects (usually $<20$ per group) who are exposed to progressively larger doses of the botanical dietary supplement to determine a safe dosage range and to identify side effects. Phase II trials are safety and efficacy studies that include larger groups of human subjects (typically numbering in the hundreds) and are longer in duration. Phase III clinical trials involve much larger groups of subjects and are intended to confirm efficacy while monitoring side effects. Finally, Phase IV studies are based on post-marketing surveillance of efficacy and safety that involve a broad range of human populations and, if applicable, long-term use of the product.

Types of Phase I trials include determination of the maximum tolerated dosage, pharmacokinetics, and investigation of drug-botanical interactions. Maximum tolerated dosage and pharmacokinetics studies are often carried out together, so that the effects of dosage on pharmacokinetics can be evaluated. During pharmacokinetics studies, serial blood draws are obtained for several hours following a single dosage of the botanical dietary supplement, and serum levels of active compounds, natural product metabolites, or marker natural products are measured (usually using LC-MS/MS). Then, pharmacokinetics parameters are calculated and include area under the concentration-time curve $(A \cup C)$, the apparent volume of distribution $\left(V_{d} / F\right)$, the apparent clearance $(C L / F)$, the peak serum concentration $\left(C_{\max }\right)$, time to reach peak concentration $\left(T_{\max }\right)$, the terminal elimination constant, and the elimination half-life $\left(T_{1 / 2}\right)$. These data help determine appropriate dosages and optimum intervals between doses, which are essential to ensure safety and efficacy. 
As an example of a Phase I escalating dosage and pharmacokinetics study, the UIC Botanical Center for Dietary Supplements Research evaluated an ethanolic extract of spent hops (Humulus lupulus hop cones that had been previously depleted of bitter acids and essential oils using supercritical fluid carbon dioxide) in a group of five postmenopausal women (Figure 8). ${ }^{47}$ This study illustrates how multiple active compounds being administered as part of a botanical extract can be monitored simultaneously during a Phase I clinical trial. In this case, UHPLC-MS/MS was used to measure all four compounds in each serum sample. By comparing these serum concentration-time curves with the levels of each compound in the original dosage, it was evident that interconversion of compounds occurred such as metabolic conversion of isoxanthohumol to 8-prenylnaringenin). Also, each compound showed long half-lives of $\sim 20$ hours that were facilitated, in part, by enterohepatic recirculation (based on the observation of secondary peaks occurring approximately $5-6 \mathrm{~h}$ post dose). 

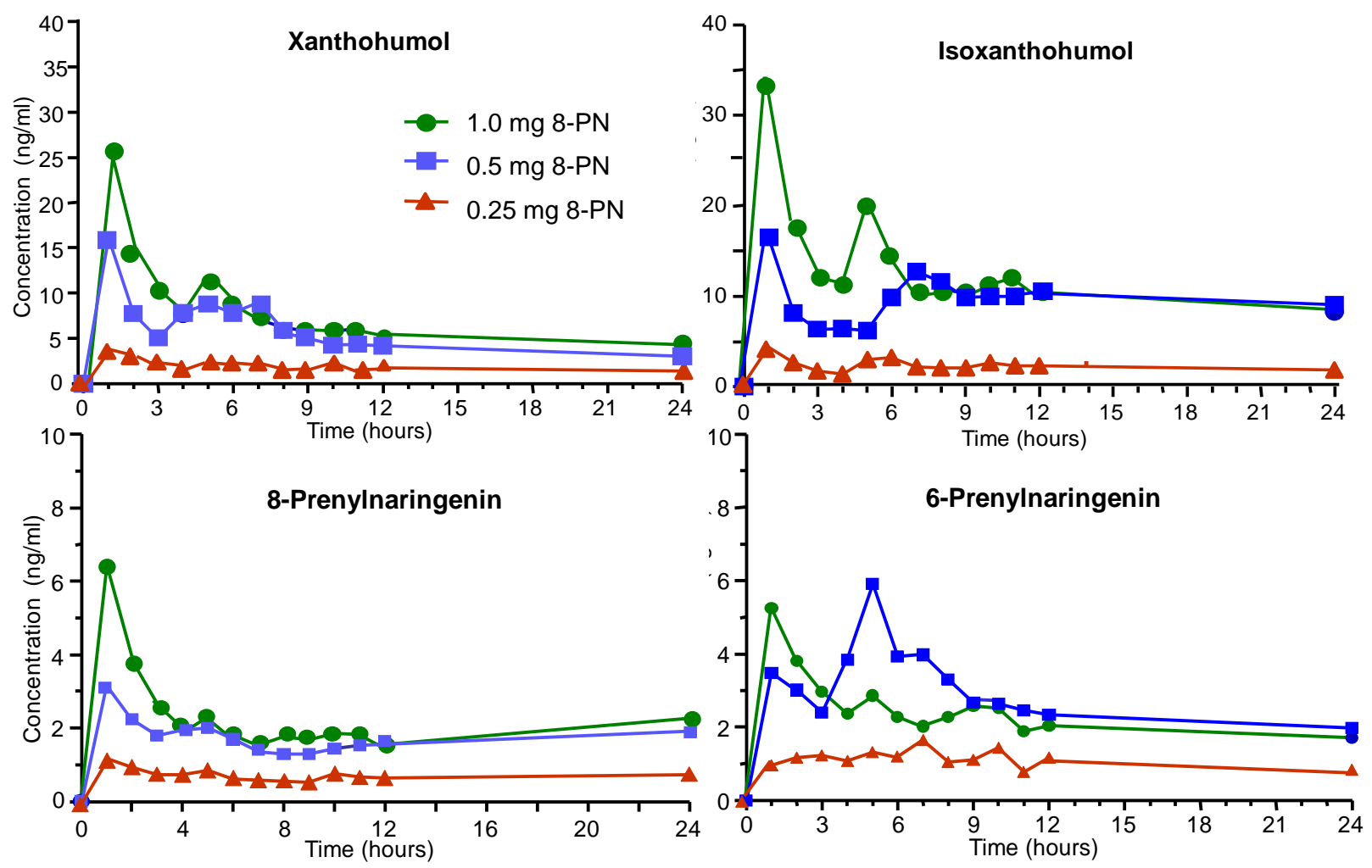

Figure 8. Serum concentration-time curves of the four major prenylated hop phenols following oral administration of single doses of an extract of spent hops to five women. (Reproduced from reference 47 with permission.)

Another type of Phase I clinical trial is designed to detect changes in pharmacokinetics of drugs resulting from drug-botanical interactions, and approaches are used that were originally developed for the clinical evaluation of drug-drug interactions. ${ }^{70}$ These studies examine the how the pharmacokinetics of probe substrates for drug metabolizing cytochrome P450 enzymes or drug transporters might be altered in subjects consuming botanical dietary supplements. In the case of phase I metabolism, the following enzymes and probe substrates may be used (note that several acceptable probes are available for most of these enzymes): midazolam for CYP3A; theophylline for CYP1A2; 
bupropion for CYP2B6; repaglinide for CYP2C8; warfarin for CYP2C9; omeprazole for CYP2C19; and desipramine for CYP2D6. ${ }^{70}$

In the case of drug transporter interactions with natural products/dietary supplements, drugs known to be substrates for particular transporters may be administered as probes along with the natural product test agent. Probe substrates are available for P-gp, OATP1B1, OATP1B3, OCT2, OAT1, OAT3, and BCPR. The selection of which enzymes and transporters to probe should be determined based on the preclinical evidence of drug-botanical interactions. The probe substrates may be administered to subjects individually or as cocktails.

Typical clinical protocols for testing drug-botanical interactions utilize 15-20 individuals per group. First, a pharmacokinetics baseline of elimination of each probe needs to be established. After oral administration of the probe(s) the first time, serial blood samples are obtained and probe concentrations are measured at each time point using LCMS/MS. Pharmacokinetics modeling is used to determine the elimination half-life $\left(t_{1 / 2}\right)$ values and other pharmacokinetic parameters for each probe. Next, the test botanical dietary supplement is administered for approximately two weeks, and then the probe substrate(s) is re-administered for another round of pharmacokinetics analysis. Differences in the pharmacokinetics before and after administration of the botanical dietary supplement indicate drug-botanical interactions. Examples of botanical dietary supplements that have been tested for drug-botanical interactions include Citrus aurantium, Echinacea purpurea, milk thistle, saw palmetto (Serenoa repens), and St. John's wort. ${ }^{77}$

In addition to utilizing botanically authenticated, standardized and GMP-produced botanical dietary supplements, Phase II clinical trials of safety and efficacy require 
appropriate clinical design. The optimum experimental design of a Phase II trial includes randomization of the subjects to different arms of the study, double-blinding so that neither the researchers or the subjects know to which treatment group a subject belongs until the study is completed, placebo-control or a cross-over design in which subjects serve as their own controls, and appropriate numbers of subjects to ensure that the results have statistical significance. In some studies, a positive control arm might also be helpful. Randomization helps avoid bias in the assignment of newly enrolled subjects to one arm of the study or to another, and double-blinding of the treatment groups helps prevent both investigator and subject bias during the study. Controls ensure that the outcomes of Phase II studies may be attributed to the botanical dietary supplements and are not caused by placebo effects or unexpected external factors. Finally, the most common flaw of Phase II clinical trials of botanical dietary supplements is insufficient power, meaning that there are too few subjects for the data to have statistical significance.

An example of a Phase II clinical trial that included all of the design elements discussed above was carried out by the UIC Botanical Center for Dietary Supplements Research and concerned the efficacy and safety of black cohosh as well as red clover (Trifolium pratense L.) for the management of menopausal vasomotor symptoms. ${ }^{41,86}$ The 12-month intervention enrolled 89 menopausal women. In addition to a placebo arm and two botanical dietary supplement arms, a positive control arm representing conventional hormone therapy $\left(\right.$ Prempro $^{\circledR}$ ) was included in the study. After 12-months, women in each arm of the study were experiencing fewer vasomotor symptoms, including the placebo group, who reported over $60 \%$ reduction in hot flashes and night 
sweats (Figure 9). Had a placebo arm not been included, the study might have suggested that red clover and black cohosh intervention had reduced vasomotor symptoms, when their effects were actually no different than placebo. No side effects were observed in women receiving either botanical dietary supplement, which is important as there had been some concern of possible liver damage by black cohosh or anticoagulant effects by red clover. The inclusion of a positive control was helpful to this otherwise negative trial, as the conventional hormone replacement arm showed that the study design could show a positive outcome (Figure 9).

$\leftarrow 1$ Black Cohosh $\multimap 3$ Placebo
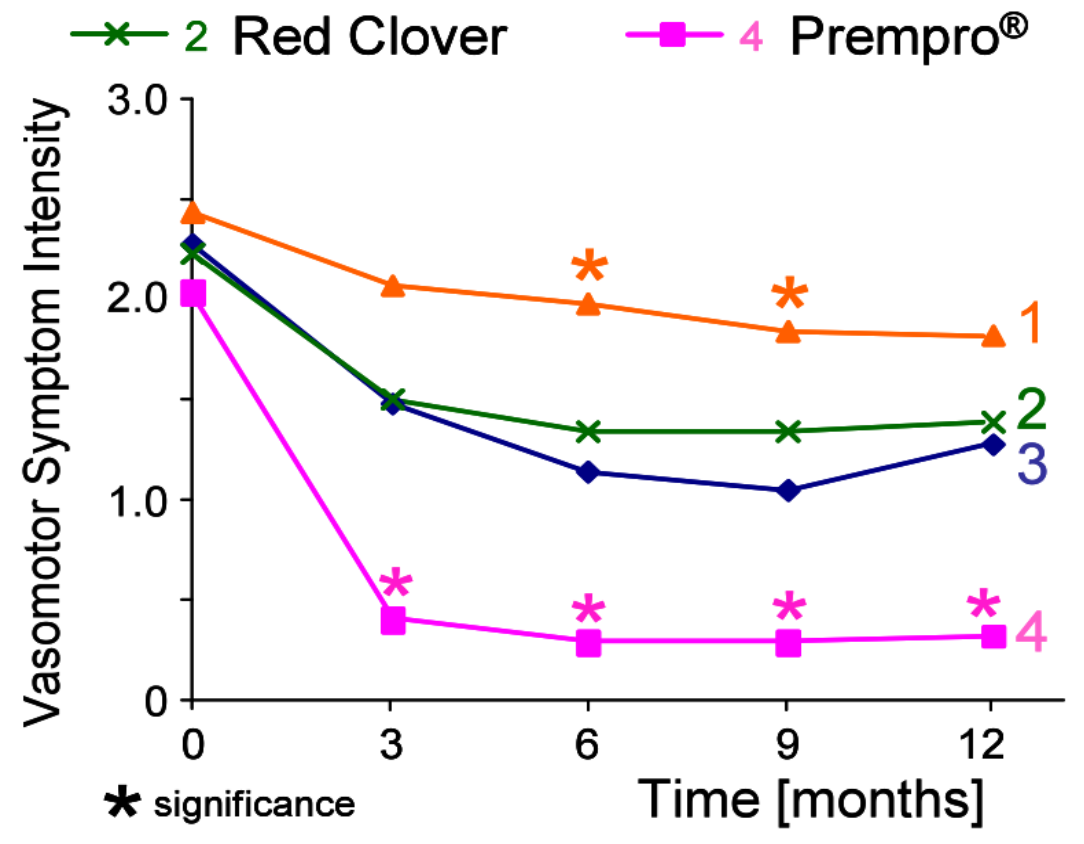

Figure 9. Reduction of vasomotor symptoms including hot flashes and night sweats as the primary outcome of a 12-month randomized, placebo-controlled, double-blind Phase II clinical trial of two botanical dietary supplements, black cohosh and red clover. The standard of care, opposed estrogen hormone therapy, was used as a positive control. (Reproduced from reference 41 with permission.) 
Whereas all Phases of clinical trials are required for drugs and botanical dietary supplements regulated as drugs, only Phase IV safety monitoring is typically carried out for most marketed botanical dietary supplements. Due to safety concerns that emerge during Phase IV surveillance, regulatory agencies have occasionally recalled specific products or banned all botanical dietary supplements containing specific botanical species. For example, the US FDA banned all dietary supplements containing ephedra (Ephedra sinica) in 2004 based on fatalities in young adults and elevated risks of myocardial infarctions, cerebrovascular accidents, seizures, and serious psychiatric illnesses. ${ }^{87}$

For botanical dietary supplements already on the market, it is unlikely that all will be evaluated using the step-wise protocol outlined in this perspective or that all will be tested using each phase of clinical trials. Clearly, producers of botanical dietary supplements intending to make therapeutic claims will need clinical evidence of both safety and efficacy and might be required by regulatory agencies to complete preclinical studies as well such as those outlined in this perspective. Even if not required, botanical dietary supplements that have been tested clinically for safety and, better still, those tested for both safety and efficacy are likely to enjoy marketing advantages over untested products. Therefore, the marketplace should provide incentives for producers to formulate botanical dietary supplements with well documented safety and defined efficacy.

\section{Conclusions and Future Directions}


As the worldwide use of botanical dietary supplements continues to grow, the need for scientific evaluation of the safety and efficacy of these products is becoming ever greater. The same rigorous preclinical and clinical approaches used to discover and develop drugs may be applied (with minor adjustments) to the investigation of botanical dietary supplements using a step-wise approach as outlined in this perspective. Among these steps, the requirement that GMP be used in the preparation of these products has contributed significantly to the safety of these products. However, additional steps such as chemical and biological standardization would help improve the reproducibility of botanical dietary supplement preparations, while additional ADME studies and clinical investigations of drug-botanical interactions would enhance our understanding of the safe use of these products. Gradually, basic science investigations of mechanisms of action and identification of active compounds will facilitate botanical dietary supplement standardization. Then, definitive clinical studies of efficacy and safety may be carried out that will establish the safe use, health benefits and limitations of these products.

\section{Acknowledgements}

Support for this perspective was provided by grant P50 AT000155 from the NIH Office of Dietary Supplements and the National Center for Complementary and Integrative Health. The author thanks all members, past and present, of the UIC/NIH Center for Botanical Dietary Supplements Research.

The author declares no competing financial interest. 
${ }^{*}$ Address correspondence to

Richard B. van Breemen, Ph.D.

Medicinal Chemistry and Pharmacognosy

833 S. Wood Street, M/C 781

Chicago, IL 60612

Tel: 312-996-9353

FAX: 312-996-7107

Email: Breemen@uic.edu 


\section{Author Biography}

Richard B. van Breemen is the Matthias C. Lu Professor of Pharmacy and Professor of Medicinal Chemistry and Pharmacognosy at the University of Illinois College of Pharmacy. He is Director of the UIC/NIH Center for Botanical Dietary Supplements Research and leads the UIC Mass Spectrometry, Metabolomics and Proteomics Facility. Dr. van Breemen received his B.A. in chemistry from Oberlin College and Ph.D. in pharmacology from the Johns Hopkins University. His research concerns the discovery and development of natural products as chemoprevention agents and the investigation of botanical dietary supplements as alternatives to conventional hormone therapy. Dr. van Breemen's uses mass spectrometry for natural product drug discovery and development and directs Phase I and II clinical trials concerning the safety and efficacy of botanical dietary supplements. 


\section{Abbreviations Used}

ADME, absorption, distribution, metabolism, and excretion; CYP, cytochrome P450; EU, European Union; US FDA, United States Food and Drug Administration; GMP, good manufacturing practice; HPLC, high performance liquid chromatography; IX, isoxanthohumol; mRNA, messenger RNA; MS, mass spectrometry; NADPH, nicotinamide adenine dinucleotide phosphate reduced form; $\mathrm{NCClH}$, National Center for Complementary and Integrative Health; P-gp, P-glycoprotein; PUF-MS, pulsed ultrafiltration liquid chromatography-mass spectrometry; 6-PN, 6-prenyInaringenin; 8PN, 8-prenylnaringenin; RAPD, randomly amplified polymorphic DNA; SRM, selected reaction monitoring; UHPLC-MS/MS, ultrahigh pressure liquid chromatography-tandem mass spectrometry; USP, US Pharmacopeial Convention; XN, xanthohumol 


\section{References}

1. Mahady, G. B. Global Harmonization of Herbal Health Claims. J. Nutr. 2001, 131, 1120S-1123S.

2. Bannerman, R.; Burton, J.; Chen, W. C. Traditional Medicine and Health Care Coverage. World Health Organization; Geneva, Switzerland: 1983.

3. Bailey, R. L.; Gahche, J. J.; Lentino, C. V.; Dwyer, J. T.; Engel, J. S.; Thomas, P. R.; Betz, J. M.; Sempos, C. T.; Picciano, M. F. Dietary Supplement Use in the United States, 2003-2006. J. Nutr. 2011, 141, 261-266.

4. http://www.marketresearch.com/Global-Industry-Analysts-v1039/HerbalSupplements-Remedies-7544379/ Accessed 3/13/2015

5. Dietary Supplement Health and Education Act of 1994. Public Law 103-417: 103rd Congress. October 25, 1994. Available at: http://dshedu.com/DSHEA Legal/dshea.html. Accessed 3/13/2015.

6. Lindstrom, A.; Ooyen, C.; Lynch, M. E.; Blumenthal, M.; Kawa, K. Sales of Herbal Supplements Increase by $7.9 \%$ in 2013, Marking a Decade of Rising Sales.

Herbalgram. 2014, 103, 52-56.

7. Ajazuddin; Saraf, S. Legal Regulations of Complementary and Alternative Medicines in Different Countries. Pharmacog. Rev. 2012, 6, 154-160.

8. Miroddi, M.; Mannucci, C.; Mancari, F.; Navarra, M.; Calapai, G. Research and Development for Botanical Products in Medicinals and Food Supplements Market. Evidence-Based Complement. Alter. Med. 2013. http://dx.doi.org/10.1155/2013/649720. Accessed 3/13/2015. 
9. Franz, C.; Chizzola, R.; Novak, J.; Sponza, S. Botanical Species Being Used for Manufacturing Plant Food Supplements (PFS) and Related Products in the EU Member States and Selected Third Countries. Food Function. 2011, 2, 720-730.

10. van Breemen, R. B.; Fong, H. H. S.; Farnsworth, N. R. The Role of Quality Assurance and Standardization in the Safety of Botanical Dietary Supplements. Chem. Res. Toxicol. 2007, 20, 577-582.

11. US Food and Drug Administration. Guidance for Industry: Current Good Manufacturing Practice in Manufacturing, Packaging, Labeling, or Holding Operations for Dietary Supplements; Small Entity Compliance Guide. December 2010. http://www.fda.gov/Food/GuidanceRegulation/GuidanceDocumentsRegulatorylnformati on/DietarySupplements/ucm238182.htm Accessed 3/13/2015.

12. FTC, Dietary Supplements: An Advertising Guide for Industry, p. 9 (Nov. 18, 1998).

13. Dolan, L. C.; Matulka, R. A.; Burdock, G. A. Naturally Occurring Food Toxins. Toxins (Basel). 2010, 2, 2289-2332.

14. https://nccih.nih.gov/research/policies/naturalproduct.htm . Accessed 3/13/2015. 15. http://apps.who.int/medicinedocs/index/assoc/s14878e/s14878e.pdf. Accessed $\underline{3 / 13 / 2015}$.

16. Xu, H.; Fabricant, D. S.; Piersen, C. E.; Bolton, J. L.; Pezzuto, J. M.; Fong, H.; Totura, S.; Farnsworth, N. R.; Constantinou, A. I. A Preliminary RAPD-PCR Analysis of Cimicifuga Species and Other Botanicals Used for Women's Health. Phytomedicine. 2002, 9, 757-762.

17. Heubl, G. New Aspects of DNA-based Authentication of Chinese Medicinal Plants by Molecular Biological Techniques. Planta Med. 2010, 76, 1963-1974. 
18. Zhang X.-J.; Huang, L.-L.; Cai, X.-J.; Li, P.; Wang, Y.-T.; Wan, J.-B. Fatty Acid

Variability in Three Medicinal Herbs of Panax Species. Chem. Cent. J. 2013, 7, 12.

Published online 2013 January 21. doi: 10.1186/1752-153X-7-12

19. Reich, E.; Schibli, A.; DeBatt, A. Validation of High-Performance Thin-Layer

Chromatographic Methods for the Identification of Botanicals in a cGMP Environment. J. AOAC Int. 2008, 91, 13-20.

20. Zhao, J.; Avula, B.; Joshi, V. C.; Techen, N.; Wang, Y. H.; Smillie, T. J.; Khan, I. A.

NMR Fingerprinting for Analysis of Hoodia Species and Hoodia Dietary Products. Planta Med. 2011, 77, 851-857.

21. Pongkitwitoon, B.; Sakamoto, S.; Morinaga, O.; Juengwatanatrakul, T.; Shoyama, Y.; Tanaka, H.; Morimoto, S. Single-Chain Variable Fragment Antibody Against Ginsenoside Re as an Effective Tool for the Determination of Ginsenosides in Various Ginsengs. J. Nat. Med. 2011, 65, 24-30.

22. Greene, L. A.; Isaac, I.; Gray, D. E.; Schwartz, S. A. Streamlining Plant Sample Preparation: The Use of High-Throughput Robotics to Process Echinacea Samples for Biomarker Profiling by MALDI-TOF Mass Spectrometry. J. Biomol. Tech. 2007, 18, 238244.

23. Eugster, P. J.; Guillarme, D.; Rudaz, S.; Veuthey, J. L.; Carrupt, P. A.; Wolfender, J. L. Ultra High Pressure Liquid Chromatography for Crude Plant Extract Profling. J. AOAC Int. 2011, 94, 51-70.

24. Mulabagal, V.; Calderón, A. I. Liquid Chromatography/Mass Spectrometry Based Fingerprinting Analysis and Mass Profiling of Euterpe oleracea (Açaí) Dietary Supplement Raw Materials. Food Chem. 2012, 134, 1156-1164. 
25. van der Kooy, F.; Maltese, F.; Hae Choi, Y.; Kyong Kim, H.; Verpoorte, R. Quality Control of Herbal Material and Phytopharmaceuticals with MS and NMR Cased Metabolic Fingerprinting. Planta Med. 2009, 75, 763-75.

26. Khan, IA. Issues Related to Botanicals. Life Sci. 2006, 78, 2033-2038.

27. Vanherweghem, J.-L.; Depierreux, M.; Tielemans, C.; Abramowicz, D.; Dratwa, M.; Jadoul, M.; Richard, C.; Vandervelde, D.; Verbeelen, D.; Vanhaelen-Fastre, R.; Vanhaelen, M. Rapidly Progressive Interstitial Renal Fibrosis in Young Women: Association with Slimming Regimen Including Chinese Herbs. Lancet, 1993, 341, 387391.

28. Vanhaelen, M.; Vanhaelen-Fastre, R.; But, P.; Vanherweghem, J.-L. Identification of Aristolochic Acid in Chinese Herbs. Lancet, 1994, 343, 174.

29. EMEA The European Agency for the Evaluation of Medicinal products, Position Paper on the Risks Associated with the Use of Herbal Products Containing Aristolochia Species. 2000, pp. 1-10.

http://www.ema.europa.eu/docs/en GB/document library/Position statement/2009/11/ WC500015537.pdf. Accessed 3/13/2015.

30. Slifman, N. R.; Obermeyer, W. R.; Aloi, B. K.; Musser, S. M.; Correll, W. A., Jr.;

Cichowicz, S. M.; Betz, J. M.; Love, L. A. Contamination of Botanical Dietary

Supplements by Digitalis lanata. N. Engl. J. Med. 1998, 339, 806-811.

31. http://www.fda.gov/ICECl/EnforcementActions/WarningLetters/2014/default.htm?

Accessed 5/26/2015.

32. http://well.blogs.nytimes.com/2015/02/03/new-york-attorney-general-targets-

supplements-at-major-retailers/? $\quad r=0$. Accessed 3/13/2015 
33. http://www.nytimes.com/aponline/2015/02/24/us/ap-us-herbal-supplementsinvestigation.html Accessed 3/13/2015.

34. Abdullah, T.; Radu, S.; Hassan, Z.; Hashim, J. K. Detection of Genetically Modified Soy in Processed Foods Sold Commercially in Malaysia by PCR-Based Method. Food Chem. 2006, 98, 575-579.

35. Weller, M. G. A Unifying Review of Bioassay-Guided Fractionation, Effect-Directed Analysis and Related Techniques. Sensors (Basel). 2012, 12, 9181-9209.

36. Shin, Y. G.; van Breemen, R. B. Analysis and Screening of Combinatorial Libraries Using Mass Spectrometry. Biopharm. Drug Dispos. 2001, 22, 353-372. Review

37. Choi, Y.; van Breemen, R. B. Development of a Screening Assay for Ligands to the Estrogen Receptor Based on Magnetic Microparticles and LC-MS. Comb. Chem. High Throughput Screen. 2008, 11, 1-6.

38. Farnsworth, N. R.; Krause, E. C.; Bolton, J. L.; Pauli, G. F.; van Breemen, R. B.; Graham, J. G. The University of Illinois at Chicago/National Institutes of Health Center for Botanical Dietary Supplements Research for Women's Health: from Plant to Clinical Use. Am. J. Clin. Nutr. 2008, 87, 504s-508s.

39. Krause, E.; Yuan, Y.; Hajirahimkhan, A.; Dong, H.; Dietz, B. M.; Nikolic, D.; Pauli, G. F.; Bolton, J. L.; van Breemen, R. B. Biological and Chemical Standardization of a Hop (Humulus lupulus) Botanical Dietary Supplement. Biomed. Chromatogr. 2014, 28, 729734.

40. Piersen, C.E.; Booth, N. L.; Sun, Y.; Liang, W.; Burdette, J. E.; van Breemen, R. B.; Geller, S. E.; Gu, C.; Banuvar, S.; Shulman, L. P.; Bolton, J. L.; Farnsworth, N. R. Chemical and Biological Characterization and Clinical Evaluation of Botanical Dietary 
Supplements: a Phase I Red Clover Extract as a Model. Curr Med Chem. 2004, 11, $1361-1374$.

41. Geller, S. E.; Shulman, L. P.; van Breemen, R. B.; Banuvar, S.; Zhou, Y.; Epstein, G.; Hedayat, S.; Nikolic, D.; Krause, E. C.; Piersen, C. E.; Bolton, J. L.; Pauli, G. F.;

Farnsworth, N. R. Safety and Efficacy of Black Cohosh and Red Clover for the Management of Vasomotor Symptoms: a Randomized Controlled Trial. Menopause. 2009, 16, 1156-1166.

42. http://www.usp.org/dietary-supplements/overview Accessed 5/27/2015.

43.http://www.aoac.org/iMIS15 Prod/AOAC/SD/SPDS/AOAC Member/SH/SPDSCF/S

PDSM.aspx?hkey=b8cbd524-33d1-4e51-8cc0-4e2028c367f2 Accessed 5/27/2015.

44. Calani, L.; Brighenti, F.; Bruni, R.; Del Rio, D. Absorption and Metabolism of Milk Thistle Flavanolignans in Humans. Phytomedicine. 2012, 20, 40-46.

45. Zhu, H. J.; Brinda, B. J.; Chavin, K. D.; Bernstein, H. J.; Patrick, K. S.; Markowitz, J. S. An Assessment of Pharmacokinetics and Antioxidant Activity of Free Silymarin Flavonolignans in Healthy Volunteers: a Dose Escalation Study. Drug Metab. Dispos. 2013, 41, 1679-1685.

46. Legette, L.; Karnpracha, C.; Reed, R. L.; Choi, J.; Bobe, G.; Christensen, J. M.; Rodriguez-Proteau, R.; Purnell, J. Q.; Stevens, J. F. Human Pharmacokinetics of Xanthohumol, an Antihyperglycemic Flavonoid from Hops. Mol. Nutr. Food Res. 2014, $58,248-255$.

47. van Breemen, R. B.; Yuan, Y.; Banuvar, S.; Shulman, L. P.; Qiu, X.; Ramos Alvarenga, R. F.; Chen, S.-N.; Dietz, B. M.; Bolton, J. L.; Pauli, G. F.; Krause, E.; Viana, M.; Nikolic, D. Pharmacokinetics of Prenylated Hop Phenols in Women Following Oral 
Administration of a Standardized Extract of Hops. Mol. Nutr. Food Res. 2014, 58, 19621969.

48. Nikolic, D.; Li, Y.; Chadwick, L. R.; van Breemen, R. B. In Vitro Studies of Intestinal Permeability and Hepatic and Intestinal Metabolism of 8-Prenylnaringenin, a Potent Phytoestrogen from Hops (Humulus lupulus L.). Pharm. Res. 2006, 23, 864-872. 49. Hidalgo, I. J.; Raub, T. J.; Borchardt, R. T. Characterization of the Human Colon Carcinoma Cell Line (Caco-2) as a Model System for Intestinal Epithelial Permeability. Gastroenterology, 1989, 96, 736-749.

50. Artursson, P.; Karlsson, J. Correlation between Oral Drug Absorption in Humans and Apparent Drug Permeability Coefficients in Human Intestinal Epithelial (Caco-2) Cells. Biochem. Biophys. Res. Comm. 1991, 175, 880-885.

51. van Breemen, R. B.; Liang, W.; Banuvar, S.; Shulman, L. P.; Pang, Y.; Tao, Y.; Nikolic, D.; Krock, K. M.; Fabricant, D. S.; Chen, S. N.; Hedayat, S.; Bolton, J. L.; Pauli, G. F.; Piersen, C. E.; Krause, E. C.; Geller, S. E.; Farnsworth, N. R. Pharmacokinetics of 23-epi-26-Deoxyactein in Women after Oral Administration of a Standardized Extract of Black Cohosh. Clin. Pharmacol. Ther. 2010, 87, 219-225.

52. Johnson, B. M.; van Breemen, R. B. In Vitro Formation of Quinoid Metabolites of the Dietary Supplement Cimicifuga racemosa (Black Cohosh). Chem. Res. Toxicol. 2003, $16,838-846$.

53. Lyons, M. M.; Yu, C.; Toma, R. B.; Cho, S. Y.; Reiboldt, W.; Lee, J.; van Breemen, R. B. Resveratrol in Raw and Baked Blueberries and Bilberries. J. Agric. Food Chem. 2003, 51, 5867-5870. 
54. Li, Y.; Shin, Y. G.; Yu, C.; Kosmeder, J. W.; Hirschelman, W. H.; Pezzuto, J. M.; van

Breemen, R. B. Increasing the Throughput and Productivity of Caco-2 Cell Permeability Assays Using Liquid Chromatography-Mass Spectrometry: Application to Resveratrol Absorption and Metabolism. Comb. Chem. High Throughput Screen. 2003, 6, 757-767. 55. Yu, C.; Shin, Y. G.; Chow, A.; Li, Y.; Kosmeder, J. W.; Lee, Y. S.; Hirschelman, W. H.; Pezzuto, J. M.; Mehta, R. G.; van Breemen, R. B. Human, Rat, and Mouse Metabolism of Resveratrol. Pharm. Res. 2002, 19, 1907-1914.

56. Wenzel, E.; Somoza, V. Metabolism and Bioavailability of trans-Resveratrol. Mol. Nutr. Food Res. 2005, 49, 472-481.

57. Guo, J.; Liu, D.; Nikolic, D.; Zhu, D.; Pezzuto, J. M.; van Breemen, R. B. In vitro Metabolism of Isoliquiritigenin by Human Liver Microsomes. Drug Metab. Dispos., 2008, 36, 461-468.

58. Guo, J.; Liu, A.; Cao, H.; Luo, Y.; Pezzuto, J. M.; van Breemen, R. B.

Biotransformation of the Chemopreventive Agent 2',4',4-Trihydroxychalchone (Isoliquiritigenin) by UDP-glucuronosyltransferases. Drug Metab. Dispos. 2008, 36, 2104-2112.

59. Cuendet, M.; Guo, J.; Luo, Y.; Chen, S.; Oteham, C. P.; Moon, R. C.; van Breemen, R. B.; Marler, L. E.; Pezzuto, J. M. Cancer Chemopreventive Activity and Metabolism of Isoliquiritigenin, a Compound Found in Licorice. Cancer Prev. Res. (Phila) 2010, 3, 221232.

60. Soars, M. G.; Gelboin, H. V.; Krausz, K. W.; Riley, R. J. A Comparison of Relative Abundance, Activity Factor and Inhibitory Monoclonal Antibody Approaches in the Characterization of Human CYP Enzymology. Br. J. Clin. Pharmacol. 2003, 55, 175-181. 
61. Guo, J.; Nikolic, D.; Chadwick, L. R.; Pauli, G. F.; van Breemen, R. B. Identification of Human Hepatic Cytochrome P450 Enzymes Involved in the Metabolism of 8Prenylnaringenin and Isoxanthohumol from Hops (Humulus lupulus L.). Drug Metab. Dispos. 2006, 34, 1152-1159.

62. Possemiers, S.; Heyerick, A.; Robbens, V.; De Keukeleire, D.; Verstraete, W. Activation of Proestrogens from Hops (Humulus lupulus L.) by Intestinal Microbiota; Conversion of Isoxanthohumol into 8-Prenylnaringenin. J. Agric. Food Chem. 2005, 53, $6281-6288$.

63. Fafii, F. The Role of Colonic Bacteria in the Metabolism of the Natural Isoflavone Daidzin to Equol. Metabolites. 2015, 5, 56-73.

64. Hill, L. L.; Foote, J. C.; Erickson, B. D.; Cerniglia, C. E.; Denny, G. S. Echinacea purpurea supplementation stimultates select groups of human gastrointestinal tract microbiota. J. Clin. Pharm. Ther. 2006, 31, 599-604.

65. Nikolic, D.; Fan, P. W.; Bolton, J. L.; van Breemen, R. B. Screening for Xenobiotic Electrophilic Metabolites Using Pulsed UItrafiltration-Mass Spectrometry. Comb. Chem. High Throughput Screen. 1999, 2, 165-176.

66. van Breemen, R. B.; Bolton, J. L. US Patent No. US 6,995,022 B1. Screening of Xenobiotics and Endogenous Compounds for Metabolic Transformation, Formation of Toxic Metabolites, and Bioavailability. Filed December 23, 1999; issued February 7, 2006. 67. Johnson, B. M.; Bolton, J. L.; van Breemen, R. B. Screening Botanical Extracts for Quinoid Metabolites. Chem. Res. Toxicol. 2001, 14, 1546-1551. 
68. Johnson, B. M.; Qu, S.-X.; Zhang, S.; Zhang, F.; Burdette, J. E.; Yu, L.; Bolton. J. L.; van Breemen, R. B. Identification of Novel Electrophilic Mammalian Metabolites of Piper methysticum Forst. (Kava). Chem. Res. Toxicol. 2003, 16, 733-740.

69. Huang, K.; Huang, L.; van Breemen, R, B. Detection of Reactive Metabolites Using Isotope-Labeled Glutathione Trapping and Simultaneous Neutral Loss and Precursor Ion Scanning with Ultra-High-Pressure Liquid Chromatography Triple Quadruple Mass Spectrometry. Anal. Chem. 2015, 87, 3646-3654.

70. FDA. Guidance for Industry. Drug Interaction Studies—Study Design, Data Analysis, Implications for Dosing, and Labeling Recommendations. February, 2012.

71. Yuan, Y.; Quu, X.; Nikolić, D.; Chen, S.-N.; Huang, K.; Li, G.; Pauli, G. F.; van Breemen, R. B. Inhibition of Human Cytochrome P450 Enzymes by Hops (Humulus lupulus) and Hop Prenylphenols. Eur. J. Pharm. Sci. 2014, 53, 55-61.

72. Yu, C.; Shin, Y. G.; Kosmeder, J. W.; Pezzuto, J. M.; van Breemen, R. B. Liquid Chromatography/Tandem Mass Spectrometric Determination of Human Cytochrome P450 Isozymes by Resveratrol and Resveratrol-3-sulfate. Rapid Commun. Mass Spectrom. 2003, 17, 307-313.

73. Li, J.; Gödecke, T.; Chen, S. N.; Imai, A.; Lankin, D. C.; Farnsworth, N. R.; Pauli, G. F.; van Breemen, R. B.; Nikolić, D. In Vitro Metabolic Interactions between Black Cohosh (Cimicifuga racemosa) and Tamoxifen via Inhibition of Cytochromes P450 2D6 and 3A4. Xenobiotica, 2011, 41, 1021-1030.

74. Foster, B. C.; Vandenhoek, S.; Tang, R.; Budzinski, J. W.; Krantis, A.; Li, K. Y. Effects of Several Chinese Natural Health Products on Human Cytochrome P450 Metabolism. J Pharm. Pharmaceut. Sci. 2002, 5, 185-189. 
75. Gurley, B. J.; Gardner, S. F.; Hubbard, M. A.; Williams, D. K.; Gentry, W. B.; Cui, Y.; Ang, C. Y. W. Cytochrome P450 Phenotypic Ratios for Predicting Herb-Drug Interactions in Humans. Clin. Pharmacol. Ther. 2002, 72, 276-287.

76. Venkataramanan, R.; Ramachandran, V.; Komoroski, B. J.; Zhang, S.; Schiff, P. L.; Strom, S. C. Milk Thistle, a Herbal Supplement, Decreases the Activity of CYP3A4 and Uridine Diphosphoglucuronosyl Transferase in Human Hepatocyte Cultures. Drug Metab. Dispos. 2000, 28, 1270-1273.

77. Gurley, B. J.; Gardner, S. F.; Hubbard, M. A.; Williams, D. K.; Gentry, W. B.; Carrier, J.; Khan, I. A.; Edwards, D. J.; Shah, A. In Vivo Assessment of Botanical Supplementation on Human Cytochrome P450 Phenotypes: Citrus aurantium, Echinacea purpurea, Milk Thistle, and Saw Palmetto. Clin. Pharmacol. Ther. 2004, 76, 428-440.

78. Schehrer, L.; Regan, J. D.; Westendorf, J. UDS Induction by an Array of Standard Carcinogens in Human and Rodent Hepatocytes: Effect of Cryopreservation. Toxicology, 2000, 147, 177-191.

79. Reinach, B.; de Sousa, G.; Dostert, P.; Ings, R.; Gugenheim, J.; Rahmani, R. Comparative Effects of Rifabutin and Rifampicin on Cytochromes P450 and UDPGlucuronosyl-Transferases Expression in Fresh and Cryopreserved Human Hepatocytes. Chem. Biol. Interact. 1999, 121, 37-48.

80. Nishimura, M.; Imai, T.; Morioka, Y.; Kuribayashi, S.; Kamataki, T.; Naito, S. Effects of NO-1886 (Ibrolipim), a Lipoprotein Lipase-Promoting Agent, on Gene Induction of Cytochrome P450s, Carboxylesterases, and Sulfotransferases in Primary Cultures of Human Hepatocytes. Drug Metab. Pharmacokinet. 2004, 19, 422-429. 
81. Jin, H.; Di, L. Permeability--In Vitro Assays for Assessing Drug Transporter Activity.

Curr. Drug Metab. 2008, 9, 911-920.

82. Tirona, R.B.; Bailey, D. G. Herbal Product-Drug Interactions Mediated by Induction.

Br. J. Clin. Pharmacol. 2006, 61, 677-681.

83. Wentworth, J. M.; Agostini, M.; Love, J.; Schwabe, J. W.; Chatterjee, V. K. K. St.

John's Wort, a Herbal Antidepressant, Activates the Steroid X Receptor. J. Endocrinol. 2000, 166, R11-R16.

84. Diana Di Mavungu, J.; Monbaliu, S.; Scippo, M. L.; Maghuin-Rogister, G.;

Schneider, Y. J.; Larondelle, Y.; Callebaut, A.; Robbens, J.; Van Peteghem, C.; De

Saeger, S. LC-MS/MS Multi-analyte Method for Mycotoxin Determination in Food

Supplements. Food Addit. Contam. Part A Chem. Anal. Control Expo. Risk Assess.

2009, 26, 885-895.

85. Soller, R. W.; Bayne, H. J.; Shaheen, C. The Regulated Dietary Supplement Industry: Myths of an Unregulated Industry Dispelled. HerbalGram. 2012, 93, 42-57.

86. Shulman, L. P.; Banuvar, S.; Fong, H. H.; Farnsworth, N. R. Discussion of a WellDesigned Clinical Trial which did not Demonstrate Effectiveness: UIC Center for Botanical Dietary Supplements Research Study of Black Cohosh and Red Clover.

Fitoterapia, 2011, 82, 88-91.

87. Food and Drug Administration. Final Rule Declaring Dietary Supplements

Containing Ephedrine Alkaloids Adulterated Because They Present an Unreasonable Risk. The Federal Register 2004, 69, 6787-6854. 
TOC Graphic

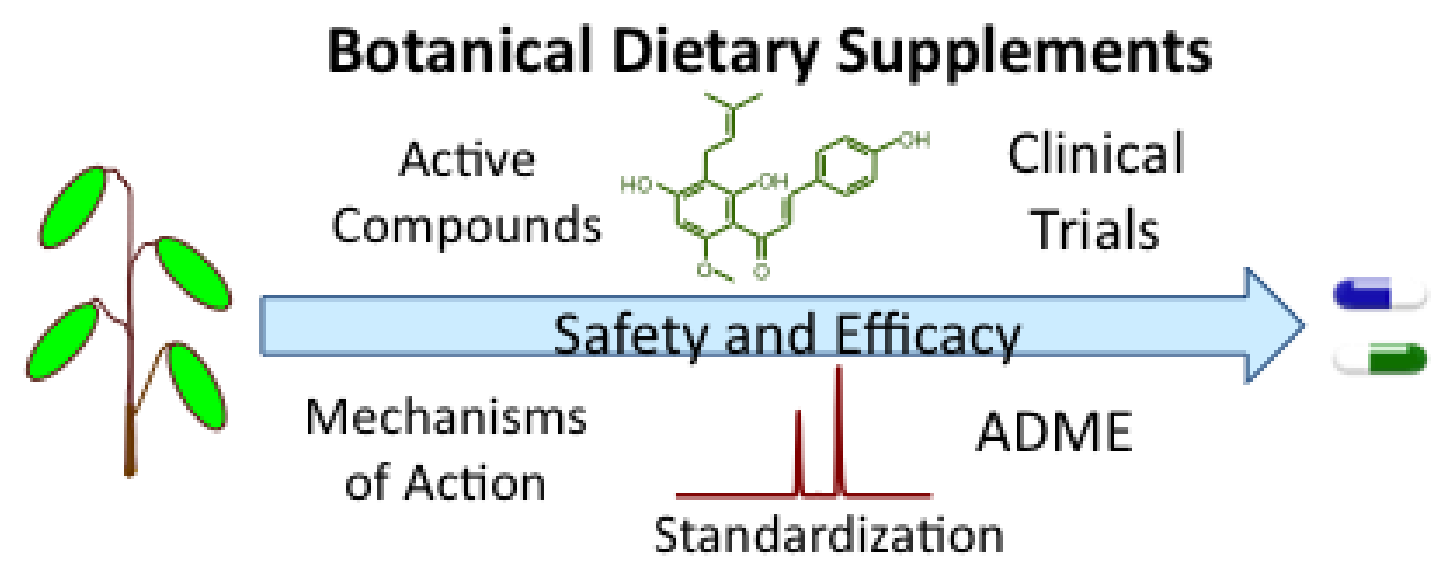

